\title{
INVESTIGATION OF POTENTIAL DUST SOURCES USING SENTINEL-1 AND NEURAL NETWORK: A CASE STUDY FROM BANDAR-E EMAM-OMIDIYE
}

\author{
S. Khoshnoud ${ }^{1}$, S.M. MirMazloumi ${ }^{2}, *$, M. Amani ${ }^{3}$, H. M. Asgari ${ }^{1}$ \\ ${ }^{1}$ Environment group , Faculty of Marine Natural Resources, Khorramshahr University of Marine Science and Technology, \\ Khorramshahr, Iran - (S. Khoshnoud) sahark.9670@gmail.com, (H. M. Asgari) h.masgari@kmsu.ac.ir \\ ${ }^{2}$ Remote Sensing Research Center, Faculty of Geodesy and Geomatics Engineering, K. N. Toosi University of Technology, Tehran, \\ Iran - mohammad.mazloumi@yahoo.com \\ ${ }^{3}$ Wood Environment \& Infrastructure Solutions, St. John's, NL, Canada, A1B 1H3 - meisam.amani@ woodplc.com
}

KEY WORDS: Dust, Sentinel-1, SAR, Neural Network, Surface Roughness

\begin{abstract}
:
Aeolian erosion is a serious environmental threat that damages soils. Dust storms are one example of the consequences of aeolian erosion in dry and semi-arid areas across the world. In this regard, soil surface roughness is an important parameter for monitoring climate changes on the Earth and modelling aeolian erosion. Synthetic Aperture Radar (SAR) systems are valuable resources for estimating soil surface roughness. In arid soils, SAR backscatter is sensitive to the soil surface roughness at higher frequencies and higher incident angles. Based on these facts and lack of studies in the field of dust and erosion using remote sensing methods, an Artificial Neural Network (ANN) along with Sentinel-1 images in two polarizations (VV and VH) were initially applied to estimate surface roughness for the first time in Bandar-e Emam-Omidiye, Khuzestan, Iran. Subsequently, the results were used to investigate potential dust sources. The parameters used to train the ANN included the radar backscatter coefficient, incident angle, and in-situ roughness. The training accuracy of the proposed ANN was relatively high with an RMSE of 0.8821 and RMSE $=0.8804$ for VH and VV polarizations respectively. These data were subsequently used to identify areas prone to dust. The results obtained from the investigation of 25 stations located in areas with five different land covers indicated accurately that locals on clay flats (RMSE=1.08) are the most prone to aeolian erosion in the form of dust.
\end{abstract}

\section{INTRODUCTION}

Dust storms are a major consequence of aeolian erosion in dry and semi-arid areas (Marticorena and Bergamet, 1995; Kemppinen et al., 2015).

Aeolian erosion of an area is controlled by vegetation density, topographic irregularities, and soil surface roughness (Marticorena et al., 2006; Shao, 2008; Sharratt and Feng, 2009; Webb and String, 2011). Soil roughness is characterized by disturbances or irregularities of the soil surface at a scale which is generally too small to be detected by a conventional topographic map or survey (Govers et al., 2000). Surface roughness affects the separation of water flow into infiltration and runoff. Moreover, monitoring the evolution of surface roughness is one approach to estimate erosion risk, particularly in agricultural areas (Zribi and Dechambre, 2003). One of the challenges in analysing surface roughness and erodibility in dust source regions is that field observations are relatively limited in space and time, and do not necessarily observe the conditions most conducive for dust emission. This limitation can be overcome to some extent using remote sensing methods, which usually produce observations with substantially higher spatial and temporal resolutions compared to field-based approaches. For example, multispectral and hyperspectral datasets have been extensively used to investigate the relationship between erodibility and soil surface properties such as crusting (Katra and Lancaster, 2008; de Jong et al., 2011).
There are generally two methods for soil roughness estimation: in situ measurements and remote sensing approaches. In situ methods are time-consuming, cost-inefficient, and labour intensive. However, remote sensing offers up-to-date, costeffective, and large coverage of vast areas. Moreover, multitemporal remote sensing datasets are considerably valuable for change detection analysis. Importantly, Synthetic Aperture Radar (SAR) systems are proficient resources for determining soil surface roughness because there is a high correlation between the surface roughness and SAR backscattering coefficient (Prigent et al., 2005; Srivastava et al., 2008; MirMazloumi and Sahebi, 2016; Zhang et al., 2016; Alexakis et al., 2017).

The incorporation of remote sensing datasets into Artificial Neural Networks (ANN) has been extensively used for various applications. ANNs can easily integrate the data collected from different remote sensing sources into an efficient algorithm. Notably, the input data in an ANN algorithm need not follow a normal distribution to be transformed into the output layers (Elshorbagy and Parasuraman, 2008; Santi et al., 2016). One of the most commonly used ANN models is Multi-Layer Perceptron (MLP). In this model, sequential neuron layers are interrelated, the weights of which control the connection power (Paloscia et al., 2013; Alexakis et al., 2017). ANNs along with SAR data have also been extensively used for soil roughness estimation. For instance, Sahebi et al. (2004) used an ANN inversion technique to estimate bare soil surface parameters from the $\mathrm{HH}$ polarization of Radarsat-1 images. Additionally,

\footnotetext{
* Corresponding author
} 
Baghdadi et al. (2012) improved roughness estimation to $0.5 \mathrm{~cm}$ using SAR data incorporated into the Calibrated Integral Equation Model (CIEM) for a wide range of soil conditions. Finally, Maleki et al., (2019) presented a two steps inversion method based on an MLP ANN. The accuracy of roughness estimated from the TerraSar-X image in the HH polarization improved from about $0.9 \mathrm{~cm}$ in the case of no prior information on roughness, to $0.57 \mathrm{~cm}$ for soil surface roughness lower than $2 \mathrm{~cm}$ and $0.54 \mathrm{~cm}$ for roughness between 2 and $4 \mathrm{~cm}$, respectively, when prior information on roughness was considered.

Different empirical models have been developed in the previous studies which investigated the sources of dust and soil erosion using SAR data. For example, Wadge and Archer (2002) developed an empirical equation between backscattering coefficient from the European Remote Sensing (ERS) and the root mean square variation of surface height profiles measured using a pin profilometer in a Tunisian playa. Prigent et al. (2005) and Marticorena et al. (2006) also determined linear relationships between the backscattering coefficient from the ERS satellites and the logarithm of aerodynamic roughness length. Moreover, Prigent et al. (2005) used aerodynamic roughness length measurements from arid regions in North America and Africa to derive a relationship between the backscattering coefficient and roughness. Finally, Tollerud and Fantle (2014) investigated surface temporal variability in the Black Rock playa, Nevada, USA using SAR satellite data between 2004 and 2010. They reported that water was a critical factor controlling playa surface evolution, and the annual time scale was crucial for investigations of playa erodibility.

The most important shortcoming of the above studies was the fact that the results of empirical models are usually less reliable in comparison to semi-empirical or theoretical models (Baghdadi et al. 2012; MirMazloumi and Sahebi, 2016). Therefore, an ANN method was used in this study to increase the accuracy and reliability of soil surface roughness retrieval.

Based on the above explanation, it is important to combine the soil roughness estimated from remote sensing methods and meteorological datasets to evaluate dust storms. Thus, this study, the first comprehensive study of the temporal evolution of surface roughness and aeolian erosion in Iran, aims to correlate meteorological datasets, dust concentration, and surface roughness changes obtained from SAR images to investigate the origin of dust and identify the potential dust storms in Khuzestan province, Iran. Therefore, the current study employs in situ measurements and SAR-derived surface roughness deserts within an ANN algorithm acquired from April 2017 to March 2018 to identify potential sources of dust storm Bandar-e Emam-Omidieh, Iran. The results of these analyses were finally validated using local meteorological datasets and were observed that clay flats are the main source of the dust storm in this region.

\section{METHOD AND MATERIALS}

\subsection{Study area}

The study area is Bandar-e Emam-Omidiye in Khouzestan province, Iran, with an area of approximately 84,147 hectares (Figure 1). In this study, the dust-possible regions in Bandar-e Emam-Omidiye were assessed in 2017. The average precipitation in this area was $127.7 \mathrm{~mm}$ in 2017, with a maximum and minimum precipitation recorded in October (73.4 $\mathrm{mm})$, and May $(0.2 \mathrm{~mm})$, respectively. This area has a warm and dry climate, with low relative humidity and high temperatures. Thus, evaporation is considerably high in this area. Based on the Department of Environment of Khuzestan province report (EPA 2012), the dust concentration was higher than permissible for a total of 53 days in this area in 2017. The longest dusty period in 2017 was 19 days and occurred in January.

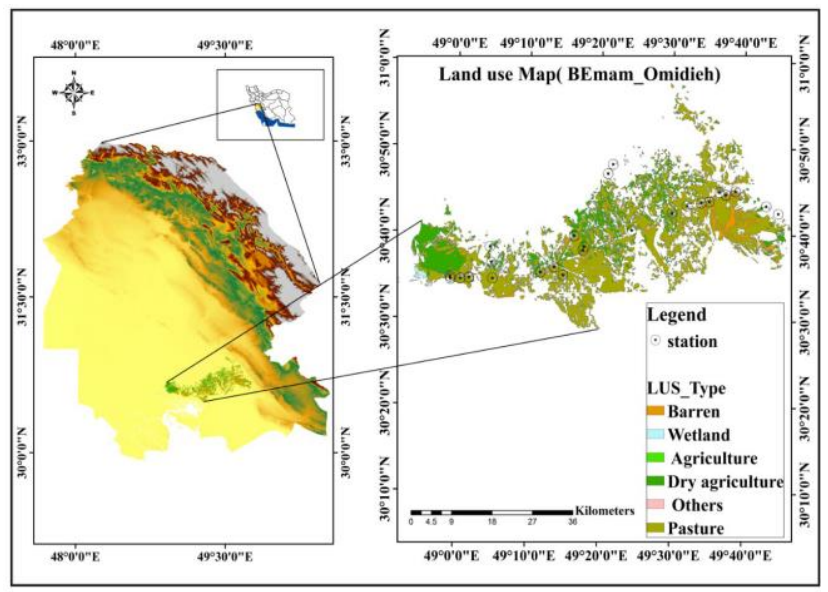

Figure 1: Study area along with various land covers found in Bandar-e Emam-Omidieh, Iran.

\subsection{Field data}

The field samples were collected simultaneously with the time of acquisition of Sentinel-1 images on 20 and 21 October 2017. The sampling stations were selected considering the land cover map of the study area (see Figure 1). As clear from this figure, various land covers, including Clay flat, Barren, Wetland, Agriculture, and Pasture (V3 and VR3) are found in this area. At each station, two vertical variation samples of soil roughness (Hrms) were collected over approximately $100 \mathrm{~m}$ in two directions: along and perpendicular to the plow direction. To calculate the surface roughness, a total of 100 images were taken. The digital images were then analyzed by the Get Data Graph software to derive the heights of the grid board images. Then, surface roughness was calculated for all the images according to the following equation:

$$
H_{r m s}=\left[\frac{1}{N-1}\left(\sum_{i=1}^{N}\left(z_{i}\right)^{2}-N(\bar{z})^{2}\right)\right]^{1 / 2}
$$

where $\mathrm{N}$ is the number of height points on the grid board, $z_{i}$ is the point height, and $\bar{z}$ is the total height.

\subsection{Satellite data}

A total of 12 Sentinel-1 images were employed in this study. The images were in the Ground Range Detected (GRD) level of processing with the Interferometric Wide (IW) swath mode. This mode provides dual polarisation ( $\mathrm{VV}$ and $\mathrm{VH})$ imagery at a resolution of $10 \mathrm{~m}$ with a swath of $250 \mathrm{~km}$. The incidence angle over the surveyed fields varies between 38 to $41^{\circ}$. Table 1 provides more properties of the images, which were used in this study.

\begin{tabular}{|l|l|}
\hline Property & Description \\
\hline Lifetime & 7 years (consumables for 12 years) \\
\hline
\end{tabular}




\begin{tabular}{|c|c|}
\hline Orbit & $\begin{array}{l}\text { Near-polar sun-synchronous orbit at } 693 \\
\mathrm{~km} \text { altitude; 12-day repeat cycle; } 175 \\
\text { orbits per cycle }\end{array}$ \\
\hline $\begin{array}{l}\text { Mean local } \\
\text { solar time }\end{array}$ & 18:00 at ascending node \\
\hline $\begin{array}{l}\text { Orbital } \\
\text { period }\end{array}$ & $98.6 \mathrm{~min}$ \\
\hline $\begin{array}{l}\text { Maximum } \\
\text { eclipse } \\
\text { duration }\end{array}$ & $19 \mathrm{~min}$ \\
\hline $\begin{array}{l}\text { Attitude } \\
\text { stabilization }\end{array}$ & 3-axis stabilized \\
\hline $\begin{array}{l}\text { Attitude } \\
\text { accuracy }\end{array}$ & $0.01^{\circ}$ (each axis) \\
\hline Instrument & $\begin{array}{l}\text { Right looking with respect to the flight } \\
\text { direction }\end{array}$ \\
\hline Steering & $\begin{array}{l}\text { Zero Doppler yaw steering and roll } \\
\text { steering }\left(-0.8^{\circ} \text { to }+0.8^{\circ}\right)\end{array}$ \\
\hline $\begin{array}{l}\text { Attitude } \\
\text { profile }\end{array}$ & Geocentric and geodetic \\
\hline $\begin{array}{l}\text { Orbit } \\
\text { knowledge }\end{array}$ & $10 \mathrm{~m}$ (each axis, $3 \boldsymbol{\sigma}$ ) using GPS \\
\hline $\begin{array}{l}\text { Operative } \\
\text { autonomy }\end{array}$ & $96 \mathrm{~h}$ \\
\hline Launch mass & $\begin{array}{l}2300 \mathrm{~kg} \quad \text { (including } \\
\text { propellant fuel) }\end{array}$ \\
\hline $\begin{array}{l}\text { Dimensions } \\
\text { (stowed) }\end{array}$ & $3900 \times 2600 \times 2500 \mathrm{~mm}$ \\
\hline $\begin{array}{l}\text { Solar array } \\
\text { average } \\
\text { power }\end{array}$ & 5900 W(end-of-life) \\
\hline $\begin{array}{l}\text { Battery } \\
\text { capacity }\end{array}$ & $324 \mathrm{Ah}$ \\
\hline $\begin{array}{l}\text { Satellite } \\
\text { availability }\end{array}$ & 0.998 \\
\hline $\begin{array}{l}\text { S-band } \\
\text { TT\&C data } \\
\text { rates }\end{array}$ & $\begin{array}{l}64 \mathrm{Kbit} / \mathrm{s} \text { telecomm and; } \\
128 \mathrm{Kbit} / \mathrm{s}-2 \mathrm{Mbit} / \mathrm{s} \text { telemetry } \\
\text { (programmable) }\end{array}$ \\
\hline $\begin{array}{l}\text { X-band } \\
\text { downlink } \\
\text { data rate }\end{array}$ & $2 \times 260 \mathrm{Mbit} / \mathrm{s}$ \\
\hline Launcher & Soyuz from kourou \\
\hline
\end{tabular}

Table 1: Sentinel-1 satellite characteristics (ESA 2017)

\subsection{Pre-processing of Satellite data}

The Level-1 GRD products were first calibrated to obtain the backscatter coefficient, using the Calibration module in the Sentinel Application Platform (SNAP) software. Then, the data were multi-looked with a window size of $2 \times 2$ using the Multilooking module in SNAP to reduce the effects of speckle noise. Terrain correction was subsequently applied for reducing geometric distortions (i.e., foreshortening, layover, and shadow) using the Range-Doppler Terrain Correction module in SNAP. For this, the Digital Elevation Model (DEM) from the Shuttle Radar Topography Mission was used. Finally, a speckle filter was applied to further reduce speckle effects while preserving the spatial resolution of the images.

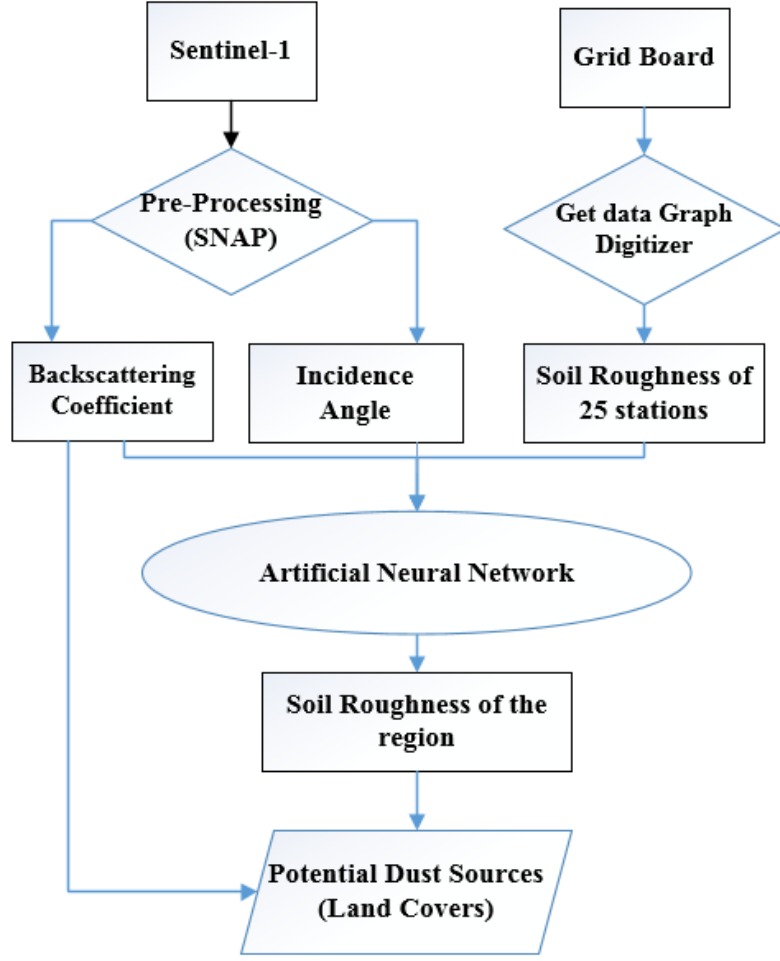

Figure 2. The flowchart of proposed method

\subsection{Implementing and training the artificial neural network}

ANN has demonstrated high potential in various remote sensing studies. ANN is a strong alternative for commonly used numerical modelling techniques which sometimes are limited by rigid normality and linearity. An ANN consists of a number of hidden neurons or nodes that work in parallel to convert data from an input to the output layer. As an example, in MLPs, successive layers of neurons are interconnected, with connection weights that control the strength of the connection.

An ANN system was trained to estimate the surface roughness from the VV and VH polarizations of the Sentinel-1 images. The parameters used to train ANN were the radar backscatter coefficient, Sentinel-1 image incident angle, and in-situ surface roughness derived from the grid panel. The result of ANN training was $\mathrm{RMSE}=0.8821$ and $\mathrm{RMSE}=0.8804$ for $\mathrm{VH}$ and $\mathrm{VV}$ polarizations respectively.

To obtain an optimized ANN architecture in terms of the total number of neurons and hidden layers, a simple ANN architecture was initially considered. Then, the errors of ANN were compared by increasing the neurons and hidden layers to obtain a more accurate ANN. The main purpose of the training process was to minimize the error between ANN output and input data by adjusting the correlation weights among them. Finally, an MLP design with three layers - (a) one input layer, (b) 10 neuron hidden layers, and (c) one output layer - was used in this study. It is also worth mentioning that $80 \%, 10 \%$, and $10 \%$ of all field samples were randomly used for training, testing, and validation, respectively. Finally, after collecting and preparing field and satellite datasets, as well as training the ANN, the model was correlated with meteorological datasets to investigate the most potential dust sources. 


\section{RESULTS AND DISCUSSION}

Figure 3 illustrates the backscattering values (for both VV and VH polarizations) for various land covers in different months from April 2017 to March 2018. In 2017, the highest backscattering value was $-11.51 \mathrm{~dB}$ at $\mathrm{VV}$ polarization in October in a Wetland area (Figure 3a). Moreover, the lowest backscattering value at the VV polarization was recorded as $17.55 \mathrm{~dB}$ in November in a Clay flat area (Figure 3b). Additionally, the highest backscattering coefficient in the VH polarization was $-19.85 \mathrm{~dB}$ in October in an Agricultural area, while the lowest VH backscatter coefficient was $-24.38 \mathrm{~dB}$ in a Barren region.

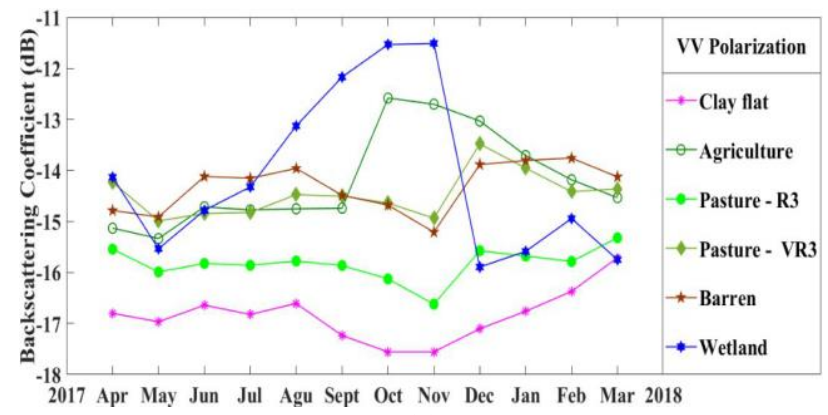

(a)

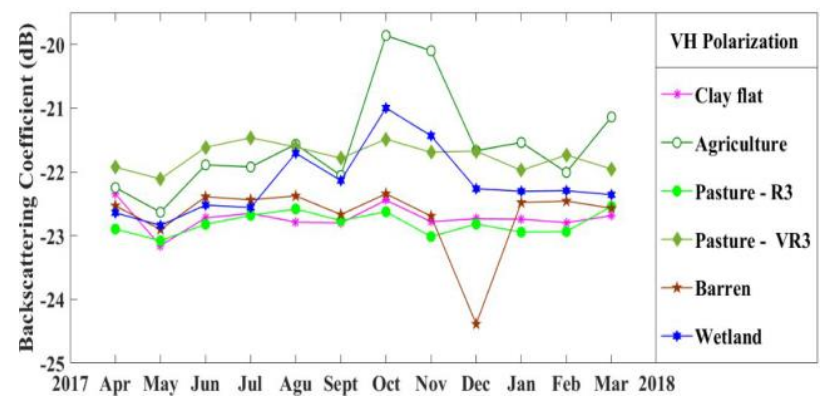

(b)

Figure 3. Backscattering Coefficients obtained from (a) VV and (b) VH polarizations between April 2017 and March 2018.

Figure 4 illustrates the estimated surface roughness from the $\mathrm{ANN}$ in the $\mathrm{VV}$ and $\mathrm{VH}$ polarizations. As is clear, the greatest surface roughness values in the VV polarization was $11.60 \mathrm{~cm}$ in a Wetland area on October 2017. Moreover, the lowest roughness in this polarization was recorded as $0.67 \mathrm{~cm}$ in June 2017 in a Clay flat region (see Figure 4 (a)). Based on Figure 4 (b), Pasture and Clay flats had the least roughness compared to Agriculture and Barren regions in the $\mathrm{VH}$ polarization. In the VH polarization, the greatest surface roughness was $7.90 \mathrm{~cm}$ in March in a Wetland area, while the lowest was $0.0006 \mathrm{~cm}$ in a Pasture area.

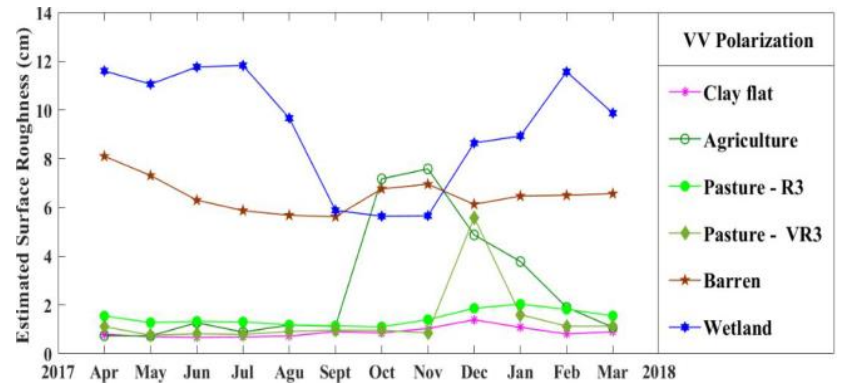

(a)

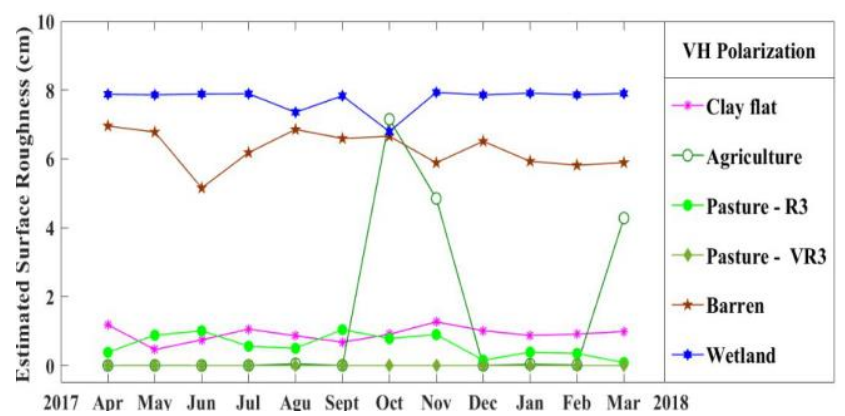

(b)

Figure 4. Estimated Surface Roughness obtained from (a) VV and (b) VH polarizations between April 2017 and March 2018

In the current study, the greatest backscattering values in both $\mathrm{VH}$ and $\mathrm{VV}$ polarizations were recorded for wetlands. In addition, based on the field surveys and land cover map of the study area (Figure 1), the most dominant land cover over the study area is Clay flat. Because pronounced levels of soil extraction cause lack of vegetation, the reducing trend of surface roughness in areas where aeolian erosion is high, such as clay flats, in the study area was justified. Based on the results provided in Tables 2 and 3, the backscattering coefficient and soil roughness values of Wetland areas in the VV polarization vary between -12.06 to $-16.36 \mathrm{~dB}$ and 5.64 to $11.82 \mathrm{~cm}$, respectively. However, the changes in the backscattering coefficients $(-16.45$ to $-14.33 \mathrm{~dB})$ and soil roughness values $(0.66$ to $1.39 \mathrm{~cm})$ for the Clay flat regions were small. This indicates the sensitivity of backscattering to soil roughness. Given the high moisture content in wetlands, the sensitivity of the backscattering coefficient to soil surface moisture seems to be higher than surface roughness. In addition, for arid soils, the backscattering values were more sensitive to roughness at higher incident angles. In this study, the lowest incident angle among the investigated land covers was $33.32^{\circ}$ for the Barren class. This may also explain the difference between the surface roughness calculated for the Barren land cover and those calculated for other land cover classes.

\section{CONCLUSIONS}

Remote sensing has a high potential to assess soil erosion caused by aeolian processes. Surface roughness is influenced by wind and this fact significantly affects radar backscattering values. For arid soils, in particular, the backscattering coefficient is very sensitive to soil surface roughness. According to the results presented here, the average soil surface roughness of Wetland areas was 8.47 and $6.84 \mathrm{~cm}$ more than Clay flats in $\mathrm{VV}$ and $\mathrm{VH}$ polarizations, respectively. In addition, the results demonstrate that Clay flats exhibited the least roughness when compared to all other land cover classes. Therefore, in our study area, Clay flats are the most prone to dust compared to the other land cover types investigated in this study.

\begin{tabular}{|l|c|c|}
\hline $\begin{array}{c}\text { Estimated Surface } \\
\text { Roughness }(\mathrm{cm})\end{array}$ & $\begin{array}{c}\text { Backscattering Coefficient } \\
(\mathrm{dB})\end{array}$ & \multirow{2}{*}{ Land Cover } \\
\hline Average Changes & Average Changes & \\
\hline
\end{tabular}




\begin{tabular}{|c|c|c|c|c|c|}
\hline 0.87 & $0.66-1.39$ & -15.21 & $\begin{array}{c}-16.45 \text { to }- \\
14.33\end{array}$ & \multicolumn{2}{|c|}{ Clay flat } \\
\hline 2.69 & $0.73-7.58$ & -13.61 & $\begin{array}{c}-14.43 \text { to }- \\
11.91\end{array}$ & \multicolumn{2}{|c|}{ Agriculture } \\
\hline 1.46 & $1.18-2.02$ & -14.55 & $\begin{array}{c}-15.21 \text { to }- \\
13.78\end{array}$ & R3 & \multirow{2}{*}{ Pasture } \\
\hline 1.38 & $0.85-5.58$ & -14.06 & $\begin{array}{c}-15.54 \text { to }- \\
12.59\end{array}$ & VR3 & \\
\hline 6.52 & $5.62-7.3$ & -12.97 & $\begin{array}{c}-14.98 \text { to }- \\
11.64\end{array}$ & \multicolumn{2}{|c|}{ Barren } \\
\hline 9.34 & $5.64-11.82$ & -13.9 & $\begin{array}{c}-16.36 \text { to }- \\
12.06\end{array}$ & \multicolumn{2}{|c|}{ Wetland } \\
\hline
\end{tabular}

Table 2. Backscattering coefficient and estimated surface roughness in VV polarization

\begin{tabular}{|c|c|c|c|c|c|}
\hline \multicolumn{2}{|c|}{$\begin{array}{l}\text { Estimated Surface } \\
\text { Roughness }(\mathrm{cm})\end{array}$} & \multicolumn{2}{|c|}{$\begin{array}{l}\text { Backscattering Coefficient } \\
\qquad(\mathrm{dB})\end{array}$} & \multirow{2}{*}{\multicolumn{2}{|c|}{ Land Cover }} \\
\hline Average & Changes & Average & Changes & & \\
\hline 0.91 & $1.17-0.46$ & -22.71 & -22.34 to -23.15 & \multicolumn{2}{|c|}{ Clay flat } \\
\hline 1.36 & $\begin{array}{c}1.04- \\
0.0001\end{array}$ & -21.55 & $-19.85 \mathrm{tc}$ & \multicolumn{2}{|c|}{ Agriculture } \\
\hline 0.58 & $2.02-1.18$ & -22.80 & -22.53 to -23.07 & R3 & \multirow[b]{2}{*}{ Pasture } \\
\hline 0.0001 & $\begin{array}{l}0.0007- \\
0.0001 \\
\end{array}$ & -21.75 & -21.37 to -22.10 & VR3 & \\
\hline 6.27 & $6.78-5.15$ & -22.68 & -22.37 to -24.38 & \multicolumn{2}{|c|}{ Barren } \\
\hline 7.75 & $91.7-6 / .9$ & -22.17 & -21.43 to -22.38 & \multicolumn{2}{|c|}{ Wetland } \\
\hline
\end{tabular}

Table 3. Backscattering coefficient and estimated surface roughness in $\mathrm{VH}$ polarization

\section{REFERENCES}

Alexakis, D., Mexis, F. D., Vozinaki, A. E., Daliakopoulos, I., \& Tsanis, I., 2017. Soil moisture content estimation based on Sentinel-1 and auxiliary earth observation products. A hydrological approach. Sensors, 17(6), 1455. https://doi.org/10.3390/s17061455

Baghdadi, N., Cresson, R., El Hajj, M., Ludwig, R. and La Jeunesse, I., 2012. Estimation of soil parameters over bare agriculture areas from C-band polarimetric SAR data using neural networks. Hydrology and Earth System Sciences, 16, pp.p-1607. https://doi.org/10.5194/hess-16-1607-2012

De Jong, S. M., Addink, E. A., Van Beek, L. P. H., \& Duijsings, D., 2011. Physical characterization, spectral response and remotely sensed mapping of Mediterranean soil surface $\begin{array}{lll}\text { crusts. } & \text { Catena, } & \text { 24-35. }\end{array}$ https://doi.org/10.1016/j.catena.2011.01.018

ESA, 2017. The Sentinel Application Platform (SNAP), a Common Architecture for all Sentinel Toolboxes Being Jointly Developed by Brockmann Consult, Array Systems Computing and C-S. Downloadable on. http://step.esa.int/main/download/ European Space Agency (ESA).

Elshorbagy, A. and Parasuraman, K., 2008. On the relevance of using artificial neural networks for estimating soil moisture content. Journal of Hydrology, 362(1-2), pp.1-18. https://doi.org/10.1016/j.jhydrol.2008.08.012
EPA, U., 40. CFR Parts 50, 51, 52, 53, and 58, 2012. National Ambient Air Quality Standards for Particulate Matter: Final Rule. Fed. Regist, 78, pp.3086-3286.

Govers, G., Takken, I. and Helming, K., 2000. Soil roughness and overland flow. Agronomie, 20(2), pp.131-146. https://doi.org/10.1051/agro:2000114

Katra, I., \& Lancaster, N., 2008. Surface-sediment dynamics in a dust source from spaceborne multispectral thermal infrared data. Remote sensing of Environment, 112(7), 3212-3221. https://doi.org/10.1016/j.rse.2008.03.016

Kemppinen, O., Nousiainen, T. and Lindqvist, H., 2015. The impact of surface roughness on scattering by realistically shaped wavelength-scale dust particles. Journal of Quantitative Spectroscopy and Radiative Transfer, 150, pp.55-67 https://doi.org/10.1016/j.jqsrt.2014.05.024

Maleki, M., Amini, J. and Notarnicola, C., 2019. Soil Roughness Retrieval from TerraSar-X Data Using Neural Network and Fractal Method. Advances in Space Research. https://doi.org/10.1016/j.asr.2019.04.019

Marticorena, B. and Bergametti, G., 1995. Modeling the atmospheric dust cycle: 1. Design of a soil-derived dust emission scheme. Journal of Geophysical Research: Atmospheres, 100(D8), pp.16415-16430. https://doi.org/10.1029/95JD00690

Marticorena, B., Kardous, M., Bergametti, G., Callot, Y., Chazette, P., Khatteli, H., Hégarat-Mascle, L., Maille, M., Rajot, J.L., Vidal-Madjar, D. and Zribi, M., 2006. Surface and aerodynamic roughness in arid and semiarid areas and their relation to radar backscatter coefficient. Journal of Geophysical Research: $\quad$ Earth $\quad$ Surface, $111(\mathrm{~F} 3)$. https:/doi/pdf/10.1029/2006JF000462

MirMazloumi, S. M., \& Sahebi, M. R., 2016. Assessment of different backscattering models for bare soil surface parameters estimation from SAR data in band C, L and P. European Journal of Remote Sensing, 49(1), 261-278. https://doi.org/10.5721/EuJRS20164915

Paloscia, S., Pettinato, S., Santi, E., Notarnicola, C., Pasolli, L. and Reppucci, A., 2013. Soil moisture mapping using Sentinel1 images: Algorithm and preliminary validation. Remote Sensing of Environment, 134, pp.234-248. https://doi.org/10.1016/j.rse.2013.02.027

Prigent, C., Tegen, I., Aires, F., Marticoréna, B., \& Zribi, M., 2005. Estimation of the aerodynamic roughness length in arid and semi-arid regions over the globe with the ERS scatterometer. Journal of Geophysical Research: Atmospheres, 110(D9). https://doi.org/10.1029/2004JD005370

Sahebi, M.R., Bonn, F. and Bénié, G.B., 2004. Neural networks for the inversion of soil surface parameters from synthetic aperture radar satellite data. Canadian Journal of Civil Engineering, 31(1), pp.95-108. https://doi.org/10.1139/103-079

Santi, E., Paloscia, S., Pettinato, S. and Fontanelli, G., 2016. Application of artificial neural networks for the soil moisture retrieval from active and passive microwave spaceborne sensors. International journal of applied earth observation and 
geoinformation, $\quad 48, \quad$ pp.61-73. https://doi.org/10.1016/j.jag.2015.08.002

Sharratt, B. and Feng, G., 2009. Friction velocity and aerodynamic roughness of conventional and undercutter tillage within the Columbia Plateau, USA. Soil and Tillage Research, 105(2), pp.236-241. https://doi.org/10.1016/j.still.2009.08.004

Shao, Y., 2008. Physics and modelling of wind erosion (Vol. 37). Springer Science \& Business Media.

Srivastava, H.S., Patel, P., Navalgund, R.R. and Sharma, Y., 2008. Retrieval of surface roughness using multi-polarized Envisat-1 ASAR data. Geocarto International, 23(1), pp.67-77. https://doi.org/10.1080/10106040701538157

Tollerud, H. J., \& Fantle, M. S., 2014. The temporal variability of centimeter-scale surface roughness in a playa dust source: Synthetic aperture radar investigation of playa surface dynamics. Remote sensing of environment, 154, 285-297. https://doi.org/10.1016/j.rse.2014.08.009

Wadge, G., \& Archer, D. J., 2002. Remote measurement of the evaporation of groundwater from arid playas. In Retrieval of Bio-and Geo-Physical Parameters from SAR Data for Land Applications, 475, pp. 165-169.

Webb, N.P. and Strong, C.L., 2011. Soil erodibility dynamics and its representation for wind erosion and dust emission models. Aeolian Research, 3(2), pp.165-179. https://doi.org/10.1016/j.aeolia.2011.03.002

Zhang, Z., Dong, Z., Li, J., Qian, G. and Jiang, C., 2016. Implications of surface properties for dust emission from gravel deserts (gobis) in the Hexi Corridor. Geoderma, 268, pp.69-77. https://doi.org/10.1016/j.geoderma.2016.01.011

Zribi, M. and Dechambre, M., 2003. A new empirical model to retrieve soil moisture and roughness from C-band radar data. Remote Sensing of Environment, 84(1), pp.42-52. https://doi.org/10.1016/S0034-4257(02)00069-X 